\title{
Inovação aberta na gestão pública: análise do plano de ação brasileiro para a Open Government Partnership
}

\author{
Rony Klay Viana de Freitas \\ Universidade Federal de Sergipe \\ Antonio Luiz Rocha Dacorso \\ Universidade Federal de Sergipe
}

\begin{abstract}
Este estudo objetivou analisar o Plano de Ação brasileiro para o Governo Aberto, baseado na teoria da inovação aberta na gestão pública. Utilizou-se de uma pesquisa documental, com vistas a aprofundar o conhecimento do fenômeno em questão. O documento foi escolhido intencionalmente, por ser exemplo basilar das políticas públicas relacionadas à inovação aberta brasileira. Os resultados mostram que os compromissos firmados pelo governo brasileiro estão consoantes com o processo de inovação aberta pública. As ações previstas no Plano estão especificamente relacionadas a transparência, abertura de dados e preparação do corpo estatal para o processo aberto de inovação.
\end{abstract}

Palavras-chave: inovação aberta; governo aberto; gestão pública.

Innovación abierta en la gestión pública: análisis del plan de acción de brasil para Open Government Partnership

Este estudio tuvo como objetivo analizar el Plan de Acción de Brasil para el Gobierno Abierto con base en la teoría de la innovación abierta en la gestión pública. Se utilizó una investigación documental, con el fin de profundizar el conocimiento en el fenómeno en cuestión. El documento fue elegido intencionadamente porque es fundamental para las políticas públicas relacionadas con la innovación abierta brasileña. Los resultados muestran que los compromisos asumidos por el gobierno brasileño son compatibles con el proceso de innovación abierta pública. En concreto, las acciones contenidas en el plan están relacionados con la transparencia, los datos abiertos y preparación de la estructura de gobierno para el proceso abierto de innovación.

Palabras clave: innovación abierta; gobierno abierto; gestión pública.

DOI: http://dx.doi.org/10.1590/0034-76121545

Artigo recebido em 20 abr. 2013 e aceito em 25 abr. 2014.

Rev. Adm. Pública - Rio de Janeiro 48(4):869-888, jul./ago. 2014 
Open innovation in public management: analysis of the Brazilian action plan for Open Government Partnership

This study aims to analyze the Brazilian action plan for Open Government, based on the theory of open innovation in public management. Documentary research was used, in order to deepen of the knowledge the phenomenon being discussed. The document was intentionally chosen because it is essential for public policies related to Brazilian open innovation The results show that the commitments made by the Brazilian government are compatible with the public open innovation process. The actions in the Plan are related specifically to transparency, open data and preparation of the governance body for the open innovation process.

KEYWORDS: open innovation; open government; public management.

\section{Introdução}

O conceito de inovação na literatura sobre ciência administrativa tem sido apresentado de forma ampla e diversa, embora a maioria dos estudos contemple um foco bem delimitado que é a inovação tecnológica (Damanpour, Walker e Avellaneda, 2009). Entretanto, convém ampliar o entendimento desse conceito para que o mesmo envolva outras perspectivas e setores, principalmente voltados para o contexto do setor público (Klering e Andrade, 2006; Damanpour, Walker e Avellaneda, 2009).

Observa-se que, enquanto o setor privado surge geralmente como pioneiro na introdução de inovações, no setor público as mudanças nestes processos ocorrem com grande defasagem temporal ou simplesmente são esquecidas (Ferrer e Lima, 2007). Conforme afirmação de Saraiva e Capelão (2000), parece inegável a existência da burocracia como fator de racionalidade predominante na esfera pública, o que acarreta uma série de atitudes, por parte do corpo administrativo, voltadas à perpetuação dos processos existentes, condizentes com a lógica de sistema fechado que os rege.

Todavia, o crescente sucesso de práticas de inovação aberta na administração de empresas privadas, conforme exposto por Chesbrough (2003), levanta a questão da aplicabilidade desses princípios para as organizações do setor público. Foi nesse contexto que surgiu a Open Government Partnership (OGP), uma iniciativa internacional, criada com a finalidade de assegurar compromissos concretos por parte dos governos de diversos países que promovam a transparência, aumentem a participação cívica, combatam a corrupção e aproveitem novas tecnologias para tornar a gestão pública mais aberta, eficaz e responsável.

Por meio da OGP, os países-membros relacionam-se com os pares, empresas e outras organizações que possam ajudar a desenvolver soluções inovadoras. Para aderir à iniciativa, cada país deve endossar uma declaração de princípios gerais e apresentar um plano de ação com compromissos assumidos, no sentido de promover um governo mais aberto, de acordo com a realidade de cada país.

Assim, o objetivo deste estudo foi analisar o plano de ação do governo brasileiro, apresentado na Open Government Partnership (OGP), à luz da teoria da inovação aberta e por 
meio de uma metodologia qualitativa, com uso do método da pesquisa documental. Destacase que não houve, nesta pesquisa, a pretensão de se confirmar a efetiva execução das ações propostas no plano de ação. A proposta ocupou-se de relacionar os conceitos teóricos ao documento e promover uma reflexão sobre a temática. Espera-se que, com este estudo, seja possível ampliar a discussão dos conceitos de inovação aberta e sua aplicabilidade na administração pública.

\section{Inovação na administração pública}

Inovar implica introduzir mudanças dentro de uma ordem existente ou planejada e, portanto, alterar elementos e introduzir aspectos valorativos, seja em instituições, em métodos, em técnicas, em formas organizacionais, em avaliação, em atitudes, em relações sociais, e supõe, sempre, inovar em relação a algo (Veiga, Costa e Carneiro, 2006). Spink (2006) aduz que, antes de se conceituar a inovação na gestão pública, é preciso compreender o contexto no qual a mesma se desenvolve.

Em outras palavras, na gestão pública, ao se definir inovação, é necessário que se leve em conta um amplo leque de possibilidades, com a premissa da necessidade de se considerarem o conjunto do sistema e os alcances e limites dos processos políticos institucionais. A inovação, nesse caso, deverá sempre se referir a uma determinada institucionalidade, no terreno das práticas sociais e de políticas em curso (Veiga, Costa e Carneiro, 2006).

No âmbito das empresas privadas, Tidd, Bessant e Pavitt (2008) sugerem que os graus de novidade das inovações podem encontrar-se (1) no nível básico: inovações "menores" (incrementos) nas quais as estruturas e componentes tendem a ser incorporados a práticas diárias e (2) no nível radical: inovações "maiores", situação na qual a organização precisa rever o conjunto de rotinas para gerenciar a inovação. Os graus de novidade podem estar posicionados entre os considerados "menores" (inovações incrementais) até os que são considerados "maiores" (mudanças radicais).

Jacobi e Pinho (2006) propõem uma extensão dessa classificação para as organizações públicas. Os autores postulam que as inovações na área governamental também podem ser separadas em duas categorias. As inovações estruturais (radicais) na área pública decorreriam de uma nova política pública, de uma nova forma de oferecer um bem público, do atendimento de setores da população até então não atendidos, isto é, uma expansão do atendimento, ou de uma nova forma de dispor componentes participantes da política pública. As inovações incrementais no setor governamental decorreriam de melhorias sucessivas em políticas vigentes, de ampliação e aperfeiçoamentos no processo estabelecido de fornecimento de bens públicos e de atendimento de setores da população.

A inovação está ao alcance de algumas iniciativas implementadas pelos governos locais

de governo que se configuram como redes de atores e de instituições motivadas em torno de muitos problemas de caráter público, dos quais as soluções ultrapassam a capacidade de ação isolada do Estado (Jacobi e Pinho, 2006). Assim, essas articulações entre os atores constituem, 
por si só, uma inovação em relação ao modelo baseado apenas na ação de um único ente estatal, bem como em relação ao processo que comumente exclui a sociedade civil das decisões.

Quanto ao balanço entre liberdade de ação e responsabilidade dos cidadãos na atuação das políticas públicas, são identificados como relevantes os conteúdos das denominadas políticas transversais (Andrade, 2001), isto é, ações focadas na inclusão social e na participação, e, consequentemente, em ações inovadoras, dentro de princípios ativos da cidadania democrática.

Nesse sentido, a administração pública deixa de lado o formato tradicional e se transforma em uma agência prestadora de serviços com foco na transparência, na responsabilidade e no cliente, em busca de um resultado perceptível para a tarefa de inserção dos cidadãos no processo. Isso se deve, conforme afirma Barrachini (2002), à democratização do acesso à informação e à facilitação da relação do cidadão com os serviços públicos prestados. Caracteriza-se assim o modelo das gestões públicas que pensam de forma inovadora.

\section{Inovação na administração pública brasileira}

As práticas de inovação nas organizações públicas brasileiras têm sido estudadas por diversos autores, com várias publicações, dentre as quais ressaltam os trabalhos desenvolvidos por Farah (1998), Pinho e Santana (2000), Andrade (2001), Torres (2004), Spink (2006), Farah (2006), Queiroz e Ckagnazaroff (2010). Esses estudos indicam que o processo de inovação no setor público tem tomado caminhos diferentes dos exercidos no passado, além de evidenciarem que as práticas de inovação das organizações privadas estão sendo cada vez mais incorporadas na administração pública brasileira.

Da descoberta do Brasil até a Revolução de 1930, o Estado brasileiro pode facilmente ser descrito como a grande instituição garantidora dos privilégios sociais e econômicos de uma elite rural, aristocrática e parasita (Torres, 2004). Esse autor destaca que as elites gravitavam em torno do Estado e lhe arrancavam os mais diversos privilégios. Além disso, havia uma política de garantia de impunidade na operação de uma infinidade de mecanismos de corrupção, clientelismo e uma lista sem fim de privilégios. Dentro desse contexto era impraticável falar em inovação.

Após os anos 1930, o setor público brasileiro experimentou uma condição relativamente ambígua: foram diversas as iniciativas de transformação e modernização, mas persistia uma estrutura bastante inflexível e fechada sobre si mesma, que resistiu soberbamente à evolução e democratização da sociedade (Torres, 2004).

Segundo Farah (2006), é a partir de 1930, no governo de Getúlio Vargas, que teve início número significativo de práticas inovadoras na gestão pública brasileira. Nesse momento houve a instituição de bases para construção de um nova perspectiva para o Estado: o de desenvolvimentista e de articulador da consolidação de uma nova identidade nacional.

No entanto, entre 1930 e o período militar, apenas uma política foi desenvolvida em relação à inovação dos processos públicos: a criação do Ministério da Desburocratização em 
1979. A principal prática inovadora foi no sentido de ressaltar que o contribuinte não é um súdito do Estado, mas um cliente com direito a boa prestação de serviços públicos.

Barrachini (2002) relata que a década de 1980 foi marcada, em um primeiro momento, pela formulação de uma agenda pública de reformas, orientadas para a democratização das políticas, do ponto de vista das decisões e da extensão do acesso às políticas públicas, principalmente devido ao fraco desempenho do governo quanto à execução de metas coletivas.

Em 1988, com a promulgação da Constituição Federal, introduziram-se alterações no perfil do federalismo, com a inauguração de um ciclo descentralizador, marcado pela transferência de recursos e encargos da União para governos estaduais e municipais (Farah, 2006). O texto constitucional brasileiro permitiu que grande parte das políticas públicas brasileiras fosse descentralizada. Também foram implementados esforços de organização e mobilização da sociedade civil, visando aperfeiçoar e incrementar as ações do poder público, especialmente nas áreas de saúde, educação e assistência social (Torres, 2004).

Jacobi e Pinho (2006) apontam que, após a promulgação da Constituição brasileira, ocorreram pressões de uma sociedade civil mais ativa e mais organizada. Dessa forma, novos espaços públicos e de interação foram sendo criados, mas principalmente de negociação. Disseminam-se, então, os conceitos de inovação dentro do corpo estatal. Nesse contexto, segundo os autores, a participação citadina emerge, principalmente, como referencial de rupturas e tensões, e a práticas participantes associadas a uma mudança qualitativa de gestão.

O grande problema surge, conforme relata Torres (2004), porque no mesmo momento em que políticas inovadoras estavam sendo disseminadas, os servidores estavam mais preocupados em fazer a defesa corporativa de seus interesses. Assim, a Constituição Federal, com seu espírito cidadão e incorporador, assumia uma enorme quantidade de atribuições sociais que exigiam uma administração pública moderna e eficiente.

Além disso, nos últimos anos os órgãos públicos têm disponibilizado em suas páginas na internet diversos serviços on-line aos cidadãos. Ademais, muitos dos entes estatais disponibilizam seus processos de execução orçamentária e financeira, tornando-se mais suscetíveis ao controle social, além de garantir um considerável grau de transparência na administração pública.

Um importante mecanismo de transparência na administração pública, apresentado por Torres (2004), é a experiência positiva obtida por meio do orçamento participativo, adotado em várias cidades brasileiras nas últimas décadas. Por essa sistemática, parte dos recursos de investimentos das prefeituras é colocada para a discussão junto à população interessada, que decide quais são as obras prioritárias para aquela cidade. Essa política abriu espaço para soluções inovadoras de aplicação do dinheiro público.

Outra significativa inovação institucional, apresentada pelo governo brasileiro, foi a Lei no 12.527, de 18 de novembro de 2011: a Lei de Acesso à informação. Esse instrumento normativo disciplina os procedimentos a serem observados pela União, estados, Distrito Federal e municípios, com o fim de garantir o acesso a informações públicas. Assim, qualquer cidadão interessado poderá apresentar pedido de acesso aos órgãos e entidades para obtenção de informações. 


\section{Inovação aberta na gestão pública}

A participação atual dos cidadãos no processo de prestação de serviços públicos é limitada; praticamente pode ser cumprida apenas na fase de avaliação final de um serviço específico. Não há nenhuma providência para envolver os cidadãos em um diálogo bidirecional com as administrações públicas. Na maioria dos casos, há uma total ausência de métodos organizados e legalmente suportados para a participação direta dos cidadãos no processo de inovação e tomada de decisão (Askounis et al., 2012).

Conforme analisa Pollit (1990), a inserção das práticas de administração privada na gestão de órgãos públicos ficou conhecida como New Public Management (NPM) ou Nova Gestão Pública (NGP). Tal processo pressupõe que as práticas de gestão de negócios, oriundas da administração privada, podem ser incorporadas pelo setor público.

Um objetivo essencial da chamada New Public Management nos últimos 20 anos foi o de entender o cidadão como um cliente de serviços públicos, e de orientar seus processos internos na direção das expectativas dos clientes (Hilgers e Piller, 2011). Os autores afirmam que, após um período de reformas com base na orientação ao cliente, existe hoje uma necessidade de integrar o cidadão ao processo decisório e, ainda, uma criação de valor coletivo entre a administração pública e seus stakeholders que podem influenciar positivamente o processo de decisão política.

Assim, surge a consciência de que o governo não pode lidar com problemas complexos sozinho. Pois, segundo relatório de 2010, da Organization for Economic Co-operation and Development (OECD), os cidadãos podem desempenhar um papel maior na realização compartilhada nas metas das políticas públicas. Consequentemente, a gestão pública deve incluir o conhecimento e a experiência dos clientes, usuários e agentes externos no processo de inovação e criação de valor: os cidadãos podem agir como colaboradores para tarefas públicas (Hilgers et al., 2009).

Neste sentido, o cidadão passa a ser visto não apenas como contribuinte, mas também como um usuário e participante dos serviços públicos. Ladeando esse aspecto, as reformas de governo durante os últimos anos contribuíram para a modernização administrativa, em matéria de qualidade, tempo e eficiência, o que gerou novas oportunidades relativas a projetos de novas estruturas organizacionais e processos, assim como a criação de uma relação externa com terceiros (Hilgers e Piller, 2011).

Nos estudos sobre administração pública, nota-se uma valorização da participação do cidadão nas decisões coletivas (Fisher, 1992; Torres, 2004) e, nessa produção, defende-se a descentralização das políticas públicas como uma forma de garantir efetividade, eficiência e eficácia nas ações estatais. Um dos fundamentos teóricos das políticas de descentralização consiste, exatamente, na vantagem de aproximar o formulador/executor e a população atingida pelas políticas públicas, o que traria maior capacidade de controle social (Torres, 2004), isto é, transparência, participação e, possivelmente, a proposição de soluções inovadoras a problemas.

Dutton (2011) reforça essa afirmação ao considerar que os cidadãos também têm o potencial de serem especialistas em questões específicas. Alguns cidadãos têm mais experiên- 
cia do que outros, ou, ainda, podem possuir conhecimentos especializados e/ou experiência particular relevante para um determinado assunto. Vistos como especialistas, o desafio para o governo não é apenas consultá-los sobre questões públicas. A proposta seria encontrar peritos na matéria, com base no mérito e em um espírito de voluntarismo, que estejam dispostos a contribuir. Esses novos papéis, aparentemente, poderiam promover um tipo de cidadãos inovadores, que desejem contribuir para criar um bem de maior valor público, alinhados com a visão da OECD (2001), que definiu governo aberto como "a transparência das ações do governo, a acessibilidade dos serviços públicos e informações, e a capacidade de resposta do governo a novas ideias, demandas e necessidades".

A efetivação da proposta de inovação aberta na gestão pública começou a se tornar visível em 2009, quando Estados Unidos, Reino Unido, Canadá e Nova Zelândia anunciaram iniciativas de abertura de suas informações públicas. No Brasil, esta disponibilização faz parte das ações do governo federal, realizadas em parceria com a Open Government Partnership (Cordeiro et al., 2012).

Segundo Torres (2004), a bibliografia especializada divide em três tipos as relações possíveis do governo aberto com terceiros, que são: G2G (relações intragovernos e intergovernos), G2B (relações estabelecidas entre a administração pública e seus fornecedores) e G2C (relações entre o governo e os cidadãos). Segundo o autor, é importante destacar as enormes possibilidades que se abrem com relação à utilização bem articulada dessas ferramentas.

Quadro 1

Tipos de relações externas do governo

\begin{tabular}{|lr|}
\hline Relação & Possibilidades de ação \\
\hline $\begin{array}{l}\text { G2G (relações intragovernos e } \\
\text { intergovernos) }\end{array}$ & - Compartilhar bancos de dados, redes de informações e cadastros que contribuiriam \\
& para o aperfeiçoamento e a economicidade na implementação de políticas públicas. \\
& - Estados e municípios de uma mesma macrorregião e com os mesmos problemas \\
& poderiam empreender esforços no sentido de resolver seus problemas de maneira \\
& cooperativa. \\
G2B (relações estabelecidas & - Utilização plena do pregão eletrônico virtual, realizado pela internet, sem nenhum \\
entre a administração pública e & relacionamento direto e pessoal entre a administração pública e os fornecedores. \\
seus fornecedores) & - Utilização do sistema de cotação eletrônica para compras. \\
G2C (relações entre o governo & - Disponibilizar serviços públicos por meio eletrônico, como marcação de consultas, \\
e os cidadãos) & inscrições na rede pública de ensino, fornecimento de certidões negativas, declaração \\
& de imposto de renda, entre outros. \\
& - Utilização do conhecimento do cidadão para solução de problemas. \\
\hline
\end{tabular}

Fonte: Adaptado de Torres (2004).

Hilgers e Piller (2011) advertem que o desenvolvimento dessas relações e a inserção dessas ações de inovação aberta na gestão pública não são instantâneos. Segundo esses autores, a abertura do processo de inovação desenvolve-se em três fases. Na etapa inicial, a inovação aberta implica transparência. 
A organização do setor público deve estar ativa e pronta para publicar todos os seus processos relevantes de políticas e de práticas administrativas (como processos parlamentares; procedimentos legislativos, desenvolvimento de instruções administrativas; contratação de servidores; procedimentos que afetam o orçamento e gestão do orçamento) em todos os níveis da administração (federal, estadual e municipal). Além disso, segundo Hilgers e Piller (2011), tem-se a exigência constante da eficiência e eficácia dos processos administrativos, transparência e rastreabilidade. Nessa fase começa-se a construir uma sensação de possível participação dos clientes/cidadãos na administração pública.

Em uma segunda etapa, transforma-se a transparência em participação. Neste ponto, a participação efetiva do cidadão se torna um meio fundamental de institucionalizar relações mais diretas, flexíveis e transparentes que reconheçam os direitos dos cidadãos (Jacobi e Pinho, 2006). Nessa fase ocorre uma abertura de diálogo entre cidadãos e Estado, aumentando a aceitação das ações do Governo (Hilgers e Piller 2011), ao mesmo tempo que se promove a participação, o que, de certa forma, implica um novo conceito de democracia. O sistema de dados abertos apresentado aos clientes/cidadãos se transforma numa plataforma que pode ser escrita, reescrita e modificada por meio de soluções inovadoras.

O tema articulador dessas ideias é a cidadania, advindo dela a questão da participação popular na gestão pública e as transformações qualitativas na relação Estado/sociedade civil, como referência de um ponto de inflexão e reforço das políticas públicas centradas na ampliação da cidadania ativa (Jacobi e Pinho, 2006).

O processo centra-se na discussão e deliberação entre os cidadãos, em vez de discursos, sessões de perguntas e respostas ou apresentações de painéis. Na preparação de reuniões ampliadas, os participantes recebem os guias detalhados para discussão e aumentam seu conhecimento das questões em consideração (OECD, 2010), para posteriormente opinar e apresentar soluções inovadoras. Assim, segundo Hilgers e colaboradores (2009), o governo pode apoiar-se em uma grande variedade de habilidades e conhecimentos do cidadão. Hilgers e Piller (2011) mostram alguns aspectos que caracterizam especificamente os processos de participação.

Quadro 2

\section{Processos de participação}

\begin{tabular}{|ll|}
\hline PROCESSO & AÇÕES \\
\hline Orçamento Popular & - Integração ativa do cidadão nas decisões orçamentárias do conselho da cidade. \\
& - Consolidação sobre a utilização dos fundos. \\
& - Discussões sobre os objetivos em relação à dotação orçamental. \\
& - Medição de resultados em relação ao orçamento. \\
Reuniões "cidade virtual” & - Processo de tomada de decisão pública. \\
("Minipúblicos"): & - Discussão de problemas relativos a todas as áreas políticas. \\
& - Apresentação de propostas para os tomadores de decisão política. \\
Definição da agenda política & - Definição dos programas prioritários do governo. \\
& - Definições das estratégias de ação. \\
Controle político & - Monitoramento dos administradores públicos e sua má conduta no sentido de uma \\
\hline
\end{tabular}

Fonte: Adaptado de Hilgers e Piller (2011). 
Em uma terceira etapa, a participação resulta em uma criação de valor colaborativa e interativa com o público. Hilgers e Piller (2011) destacam que a base desse pilar é a premissa de que certos procedimentos no sistema administrativo podem ser concebidos de modo muito mais eficaz se o processo de inovação for aberto. Os autores ainda propõem que, além das reformas administrativas tecnocráticas de governo eletrônico, existe uma questão principal que é a de reforçar a cooperação intra-administrativa e adotar um sistema no qual organizações possam ir para além das fronteiras internas, criando relações com outros órgãos públicos, empresas, redes e cidadãos.

Nesse sentido, conforme propõe Angelis (2013), o valor público não é mais fornecido somente pelo governo, mas sim pela colaboração. O papel das gestões públicas se estende para a edificação da inteligência e resiliência com os cidadãos, empresas e outros órgãos e até outros países, por meio da capacidade coletiva para aprender, mudar e se adaptar ao ambiente.

Tais processos colaborativos devem entender e envolver a sociedade não apenas como usuária e que faz escolhas, mas também como criadora e formadora de políticas (Torres, 2007). Hilgers e Piller (2011) citam algumas características do desenvolvimento dessa terceira etapa de abertura do processo de inovação pública.

Quadro 3

Processos de colaboração

\begin{tabular}{|c|c|}
\hline PROCESSO & AÇÕES \\
\hline $\begin{array}{l}\text { Planejamento } \\
\text { urbano }\end{array}$ & $\begin{array}{l}\text { - Planejamento e concepção do espaço público por aquelas pessoas que vivem e trabalham } \\
\text { no mesmo. Os próprios cidadãos, juntamente com os governantes, propõem as políticas de } \\
\text { desenvolvimento urbano. } \\
\text { - Desenvolver planos de desenvolvimento urbano com deliberação e ações inovadoras da sociedade. }\end{array}$ \\
\hline $\begin{array}{l}\text { Inovação pública } \\
\text { e competições de } \\
\text { ideias }\end{array}$ & $\begin{array}{l}\text { - Oferecer apoio econômico e humanitário global por meio da organização de concursos de ideias } \\
\text { para solução de problemas públicos. } \\
\text { - Desenvolvimento e busca de inovações no campo da saúde, educação, agricultura, comércio etc. } \\
\text { - Oferecimento de recompensas por soluções inovadoras para problemas específicos. }\end{array}$ \\
\hline $\begin{array}{l}\text { Mapas públicos e } \\
\text { melhoria contínua } \\
\text { aberta }\end{array}$ & $\begin{array}{l}\text { - Publicação de mapas oficiais permitindo que os cidadãos, de forma autônoma, denunciem aos } \\
\text { governantes problemas públicos de infraestrutura (através de fotos), com vistas a sinalizar os } \\
\text { problemas para futura manutenção. } \\
\text { - Permitir aos cidadãos transmitir sugestões de melhoria e notificações de reclamações em tempo real. }\end{array}$ \\
\hline $\begin{array}{l}\text { Intercâmbio de } \\
\text { patentes }\end{array}$ & $\begin{array}{l}\text { - A integração de colaboradores externos nos processos de pedidos de patentes. O público em geral } \\
\text { pode analisar as patentes e fornecer dicas de melhorias aos projetos. Deste modo, os examinadores } \\
\text { de patentes são apoiados por peritos externos, após convite aberto de participação, permitindo assim } \\
\text { uma divisão altamente especializada do trabalho visando um aumento da qualidade de patentes. }\end{array}$ \\
\hline
\end{tabular}

Fonte: Adaptado de Hilgers e Piller (2011).

A plataforma colaborativa da web 2.0 é outro exemplo que possibilita concretizar ações até aqui impossíveis na nossa sociedade, como o relacionamento de "muito para muitos" à distância, comunidades virtuais, listas de discussão, soluções criativas e inovadoras por meio da participa- 
ção dos cidadãos (Cordeiro et al., 2012). Murray, Caulier-Grice e Mulgam (2010) acrescentam que essa colaboração possibilita a criação de um maior valor público para a sociedade.

O fato é que, nas administrações públicas, essas possibilidades de ação ficam absolutamente subaproveitadas. Torres (2004) afirma que, em muitos casos, uma mesma e única estrutura administrativa poderia atender às demandas de determinado programa ou atividade necessários em alguns municípios ou estados, porém nenhum esforço mais deliberado é feito no sentido de se aproveitar essas potencialidades.

Com o processo de inovação calcado nesses três pilares, o acesso ao governo pode ser estendido para além dos serviços comuns, alcançando outra esfera qualitativa em termos de interação republicana (Ruediger, 2006). Com isso, segundo o autor, haveria uma efetiva capacidade de accountability e interlocução entre decisores e cidadãos (que também se tornariam decisores), bem como de provimento de informações com real valor agregado para discussão da agenda pública.

\section{Procedimentos metodológicos}

Para a produção deste artigo foi adotada uma estratégia qualitativa, com o objetivo de interpretar as características do fenômeno estudado. O método de pesquisa utilizado foi a pesquisa documental. Apesar de esse método ser considerado, por diversos autores (Vergara, 2005; Saunders, Lewis e Thornill, 2007), uma técnica complementar em pesquisa, Silva e colaboradores (2009) defendem que pesquisa documental não é apenas uma técnica ou procedimento de coleta de dados, mas sim um método de pesquisa.

Os documentos são utilizados como fontes de informações, indicações e esclarecimentos, e seu conteúdo permite elucidar determinadas questões e servir de prova para outras, de acordo com o interesse do pesquisador (Figueiredo Sá-Silva, Almeida e Guidani, 2009). Ademais, o documento escrito constitui, ainda, uma fonte extremamente preciosa para todo pesquisador em ciências sociais (Cellard, 2008). O método se vale de documentos originais, que ainda não receberam tratamento analítico por nenhum autor (Godoy, 1995; Helder, 2006; Sá-Silva, Almeida e Guidani, 2009), ou que podem ser reexaminados, buscando-se novas e/ ou interpretações complementares (Godoy, 1995).

A pesquisa documental permite ainda a investigação de problemas de forma indireta, por meio do estudo dos documentos que são produzidos pelo homem e por isso revelam o seu modo de ser, viver e compreender um fato social (Silva et al., 2009). Nesse sentido, conforme defende Godoy (1995), acredita-se que a pesquisa documental se constitui em uma forma que se reveste de um caráter inovador, ao trazer contribuições importantes no estudo de alguns temas.

Em seguida, foi definida como amostra documental (que também serviu como unidade de análise), no presente estudo, o plano de ação brasileiro apresentado na Open Government Partnership, pois é esse documento que contém as propostas de inovação aberta do governo brasileiro, o tema desta investigação. Destaca-se que esse é o único documento que engloba o planejamento das ações brasileiras. 
Após a determinação da unidade de análise, foram identificadas as categorias de análise (Godoy, 1995). O estudo procurou classificar as ações previstas no plano de ação em transparência, participação e colaboração, em consonância com a proposta de Hilgers e Piller (2011).

\section{A participação brasileira na Open Government Partnership}

A Open Government Partnership (OGP) constitui-se em iniciativa internacional criada com a finalidade de assegurar compromissos concretos por parte dos governos de diversos países para promover a transparência, aumentar a participação cívica, combater a corrupção e aproveitar novas tecnologias para tornar governos mais abertos, eficazes e responsáveis (OGP, 2011).

A iniciativa foi lançada oficialmente em setembro de 2011, quando os governos de oito países fundadores (Brasil, Indonésia, México, Noruega, Filipinas, África do Sul, Reino Unido e Estados Unidos) aprovaram uma Declaração de Governo Aberto e anunciaram seus planos de ação nacionais que atenderiam aos objetivos da OGP. A OGP é liderada por uma Comissão de Coordenação. Essa comissão é formada por dois países-membros que se alternam periodicamente.

\subsection{O plano de ação brasileiro e a inovação aberta}

A primeira parte do Plano de Ação brasileiro contém uma introdução em que é feita uma apresentação geral de como foi elaborado o documento. A segunda parte contém um resumo das principais ações governamentais já existentes referentes à abertura do processo de inovação. Essa seção do documento destaca programas, projetos e estratégias que já foram implementados e outros em andamento no país. Em seguida, passa-se a balizar os compromissos a serem realizados pelo governo. As ações previstas estão relacionadas aos projetos governamentais com suas práticas de transparência, participação e inovação.

Os primeiros compromissos firmados estão relacionados com a política de Aumento da Integridade Pública, na micropolítica do Sistema Federal de Acesso à Informação.

Todas as ações desse primeiro compromisso estão relacionadas à primeira fase do processo de abertura de inovação, ou seja, a transparência. Segundo o plano de ação brasileiro (de 2011), tais ações relacionadas objetivam desenvolver os procedimentos e adquirir a experiência necessária para a implantação do Sistema Federal de Acesso à Informação. Com isso, o governo pretende criar o ambiente adequado e programar as políticas vindouras relacionadas à abertura do processo de inovação.

Essas ações são extremamente relevantes, tanto para a administração pública quanto para a sociedade, pois os esforços e as transformações que visam a aumentar os níveis de transparência, accountability e responsabilização dos dirigentes públicos brasileiros requerem uma análise mais detalhada (Torres, 2004), bem como requerem uma preparação do corpo estatal para tais ações. 
Quadro 4

Ações referentes ao aumento da integridade pública

\begin{tabular}{|c|c|c|}
\hline Área & Ações & $\begin{array}{l}\text { Classificação } \\
\text { no processo de } \\
\text { inovação aberta }\end{array}$ \\
\hline \multirow{8}{*}{$\begin{array}{l}\text { Sistema } \\
\text { Federal de } \\
\text { Acesso à } \\
\text { Informação }\end{array}$} & $\begin{array}{l}\text { Pesquisa de diagnóstico sobre valores, conhecimento e cultura de acesso à informação } \\
\text { pública no Poder Executivo Federal Brasileiro. }\end{array}$ & Transparência \\
\hline & $\begin{array}{l}\text { Estudo de diagnóstico sobre o papel das Ouvidorias dos órgãos e entidades do Poder } \\
\text { Executivo federal na Política Brasileira de Acesso a Informações Públicas. }\end{array}$ & Transparência \\
\hline & Elaboração de Guia e/ou Cartilha sobre acesso à informação para servidores públicos. & Transparência \\
\hline & $\begin{array}{l}\text { Realização de pesquisa para identificação das demandas da sociedade sobre acesso à } \\
\text { informação, visando ao aperfeiçoamento da política de transparência ativa. }\end{array}$ & Transparência \\
\hline & $\begin{array}{l}\text { Desenvolvimento de modelo para a estruturação dos serviços de informações ao } \\
\text { cidadão em órgãos e entidades do Poder Executivo Federal e de procedimentos para o } \\
\text { funcionamento do sistema de acesso a informações públicas. }\end{array}$ & Transparência \\
\hline & Elaboração de Curso EaD para capacitação de servidores públicos no tema Acesso à Informação. & Transparência \\
\hline & $\begin{array}{l}\text { Elaboração e oferta de cursos de capacitação de servidores públicos em temas referentes a } \\
\text { gestão da informação. }\end{array}$ & Transparência \\
\hline & $\begin{array}{l}\text { Elaboração de Catálogo de Dados e Informações Públicas disponibilizados na internet por } \\
\text { órgãos e entidades da administração pública federal. }\end{array}$ & Transparência \\
\hline
\end{tabular}

Fonte: Elaborado pelos autores (2013).

Em seguida são apresentados os compromissos ligados diretamente com o processo de transparência e abertura dos dados governamentais.

As ações previstas na segunda seção de compromissos também estão relacionadas ao pilar da transparência. As propostas dizem respeito à criação de uma estrutura estatal que esteja preparada para a gestão da inovação aberta e a definição de uma política para armazenagem de dados em um banco único pelo governo. Verifica-se que as propostas estão orientadas pelos princípios de dados abertos mencionados por Hilgers e Ihl (2010).

Nessa seção, verifica-se o interesse do governo brasileiro em se relacionar com a sociedade de novas maneiras e a disponibilizar conteúdos e formatos de informações que atendam a interesses de diferentes públicos. O governo brasileiro compromete-se também a implementar soluções de abertura de dados e promover o aumento da integridade das informações públicas, por meio de uma plataforma aberta. Assim, percebe-se que a tecnologia da informação desempenha um papel relevante no sentido de trazer a transparência e disponibilizar as informações públicas que a sociedade tanto requer (Torres, 2004).

Outra preocupação do governo brasileiro é a de preparar seus recursos humanos com capacitações e ações educacionais relacionadas aos processos de inovação aberta. Essa ação, conforme afirma Torres (2004), majora as chances e oportunidades para que as políticas públicas sejam implantadas e ajustadas de maneira a ganhar em eficiência e eficácia. Ainda 
segundo o autor, a ampla difusão da informação também abre oportunidades para que o usuário/cidadão possa interagir com os formuladores/executores, com provável ganho no aprimoramento de políticas públicas.

\section{Quadro 5 \\ Ações referentes a transparência e abertura de dados}

\begin{tabular}{|c|c|c|}
\hline Área & Ações & $\begin{array}{l}\text { Classificação } \\
\text { no processo de } \\
\text { inovação aberta }\end{array}$ \\
\hline \multirow{9}{*}{$\begin{array}{l}\text { Transparência Ativa } \\
\text { e Dados Abertos }\end{array}$} & Definição e Construção do Data Warehouse do Portal da Transparência. & Transparência \\
\hline & Reestruturação do Portal da Transparência. & Transparência \\
\hline & $\begin{array}{l}\text { Disponibilização de dados do Sistema de Gestão de Convênios e Contratos de } \\
\text { Repasse (Siconv) em formato de dados abertos. }\end{array}$ & Transparência \\
\hline & $\begin{array}{l}\text { Construção da Plataforma para Gestão de Informação Estratégica em Ciência, } \\
\text { Tecnologia e Inovação. }\end{array}$ & Transparência \\
\hline & $\begin{array}{l}\text { Infraestrutura Nacional de Dados Abertos (Inda): conjunto de padrões, tecnologias, } \\
\text { procedimentos e mecanismos de controle necessários para atender às condições de } \\
\text { disseminação e compartilhamento de dados e informações públicas. }\end{array}$ & Transparência \\
\hline & Desenvolvimento da Infraestrutura Nacional de Dados Abertos. & Transparência \\
\hline & $\begin{array}{l}\text { Plano de capacitação da Inda: plano de capacitação para servidores públicos federais, } \\
\text { para aumentar a qualidade dos dados disponibilizados pelo governo. }\end{array}$ & Transparência \\
\hline & $\begin{array}{l}\text { Ações de disseminação: delineamento e implementação de linha temática sobre } \\
\text { dados abertos. }\end{array}$ & Transparência \\
\hline & Portal Brasileiro de Dados Abertos: desenvolvimento de ambiente virtual. & Transparência \\
\hline
\end{tabular}

Fonte: Elaborado pelos autores (2013).

A terceira seção de compromissos contém ações relacionadas à área de aumento da integridade pública, e, em sua primeira parte, trata da participação social e do engajamento direto do cidadão.

Quadro 6

Ações referentes à participação social

\begin{tabular}{|lll|}
\hline \multicolumn{1}{|c}{ Área } & \multicolumn{1}{c}{ Ações } & $\begin{array}{c}\text { Classificação no processo } \\
\text { de inovação aberta }\end{array}$ \\
\hline & Realização da 1a Conferência Nacional sobre Transparência e Controle Social & Transparência / Participação \\
Participação & Realização do Seminário Nacional de Participação Social & Transparência / Participação \\
Social e & Realização de Encontros do Fórum Interconselhos PPA 2012-15 & Transparência / Participação \\
Engajamento & Filiação e Celebração de parceria com a organização W3C Brasil3 & Transparência \\
Cidadão & Celebração de parceria com o Laboratório de Cultura Digital & Transparência \\
& Realização do I Encontro Nacional de Dados Abertos & Transparência / Participação \\
\hline
\end{tabular}

Fonte: Elaborado pelos autores (2013). 
Verifica-se que as ações apresentadas propõem a participação direta do cidadão em planejamento de decisões. Entretanto, esse planejamento não constitui ações relacionadas com a participação direta do cidadão nas políticas sociais. A proposta do governo brasileiro é o debate com a sociedade em relação aos próprios eixos temáticos da política do governo aberto: promoção da transparência, controle social, participação da sociedade no controle da gestão.

Assim, a proposta de participação objetiva significa, na realidade, "apresentar" à sociedade os futuros mecanismos e instâncias de participação social. Outro destaque é a intenção de incentivar os governos de outras esferas (estadual e municipal) a iniciarem o processo de abertura de dados e a utilizarem a política de dados abertos como plataforma de colaboração com a sociedade.

A segunda parte de compromissos apresentados no Plano de Ação está relacionada com a política de gestão efetiva de recursos públicos. As primeiras ações dessa seção pertencem à micropolítica de Transparência Orçamentária e Gestão de Recursos Públicos.

Quadro 7

Ações referentes à gestão efetiva de recursos públicos

\begin{tabular}{|c|c|c|}
\hline Área & Ações & $\begin{array}{l}\text { Classificação } \\
\text { no processo de } \\
\text { inovação aberta }\end{array}$ \\
\hline \multirow[t]{2}{*}{$\begin{array}{l}\text { Transparência } \\
\text { Orçamentária e } \\
\text { Gestão de Recursos } \\
\text { Públicos }\end{array}$} & $\begin{array}{l}\text { Plano de Desenvolvimento da Escola (PDE Escola Interativo) } \\
\text { Facilitação do acesso a bases de dados específicas no Portal da } \\
\text { Transparência }\end{array}$ & $\begin{array}{l}\text { Transparência } \\
\text { Transparência }\end{array}$ \\
\hline & Disponibilização de dados do Cadastro Unificado de Fornecedores (Sicaf) & Transparência \\
\hline \multirow[t]{2}{*}{$\begin{array}{l}\text { Licitações e } \\
\text { Contratos Públicos }\end{array}$} & Registro de Preços Nacionais da Educação & $\begin{array}{l}\text { Transparência / } \\
\text { Participação }\end{array}$ \\
\hline & Contratação e Gestão Contratual de Serviços de Tecnologia da Informação & Transparência \\
\hline
\end{tabular}

Fonte: Elaborado pelos autores (2013).

Quanto ao uso do dinheiro público, as ações estão relacionadas apenas à disponibilização de ferramentas para consultas específicas sobre a destinação do dinheiro público. Aparentemente, ainda não foi concebida como interação do cidadão na apresentação de propostas inovadoras para utilização do orçamento. Os compromissos são basicamente de disponibilização dos planos de ação escolares, que, segundo o próprio plano de ação, buscará auxiliar as escolas na melhoria da qualidade de ensino e aprendizagem por meio de uma plataforma eletrônica.

As outras duas medidas estão relacionadas à facilitação do acesso, por parte dos cidadãos, a informações de ferramentas já existentes no governo. A proposta é ampliar a transparência, visto que a publicação de dados será mais detalhada no que se refere aos fornecedores do governo federal através do portal de compras públicas do governo federal: ComprasNet.

Entretanto, nessa seção não foi especificada uma importante ferramenta já em uso em muitas gestões: o orçamento participativo. Basicamente, essa política representa a retirada de 
parte da peça orçamentária dos centros tradicionais de decisão (o Executivo e o Legislativo) disponibilizando-a para debates junto à sociedade organizada (Torres, 2004), que decidirá a destinação de parte do dinheiro público.

No que diz respeito aos processos de aquisição e ao relacionamento com fornecedores, foi proposto um modelo de compras centralizadas, o Registro de Preços Nacional, planejado para atender a todos os estados e municípios. A proposta dessa ação é tornar possível a realização de um único procedimento licitatório, centralizado, gerando economia nas compras e diminuição do tempo dos processos de licitação para aquisição de bens escolares.

A outra política com a qual se compromete o governo brasileiro é a melhoria do processo de compras e o fornecimento de serviços de tecnologia da informação. Busca-se a racionalização do processo de contratação e gestão contratual de serviços, bem como consolidar as políticas de governança na área tecnológica de compras. Verifica-se uma proposta de abertura da inovação na relação entre governo e fornecedores.

A seguir, são apresentadas as modificações propostas para o aumento da Responsabilidade Corporativa, a prevenção da corrupção e a melhoria da prestação dos serviços públicos diretos.

Quadro 8

Ações referentes à responsabilidade corporativa e prestação de serviços públicos

\begin{tabular}{|c|c|c|}
\hline Área & Ações & $\begin{array}{c}\text { Classificação no processo } \\
\text { de inovação aberta }\end{array}$ \\
\hline $\begin{array}{l}\text { Prevenção da } \\
\text { Corrupção }\end{array}$ & $\begin{array}{l}\text { Implementação do Cadastro Empresa Pro-Ética } \\
\text { Contratação e Gestão Contratual de Serviços de Tecnologia da } \\
\text { Informação }\end{array}$ & $\begin{array}{l}\text { Transparência } \\
\text { Transparência }\end{array}$ \\
\hline $\begin{array}{l}\text { Mapeamento } \\
\text { da Prestação de } \\
\text { Serviços Públicos }\end{array}$ & $\begin{array}{l}\text { Integração Sistêmica de Ouvidorias } \\
\text { Política de Formação Continuada para as Ouvidorias Públicas do Poder } \\
\text { Executivo Federal }\end{array}$ & $\begin{array}{l}\text { Transparência / Colaboração } \\
\text { Transparência / Participação }\end{array}$ \\
\hline $\begin{array}{l}\text { Serviços On-line ao } \\
\text { Cidadão }\end{array}$ & Portal Guia de Serviços Públicos & Participação \\
\hline
\end{tabular}

Fonte: Elaborado pelos autores (2013).

Em grandes linhas, conforme afirma Torres (2004), essas ações previstas, relacionadas à transparência e à disponibilização da informação no setor público, consagram, entre outros, dois grandes objetivos: atacar o importante problema da corrupção e propiciar o aperfeiçoamento constante das ações estatais.

Verifica-se nessa seção uma iniciativa que busca contribuir para o estabelecimento de um ambiente que vai além da transparência. A integração sistêmica das ouvidorias permite a interlocução construtiva entre o Estado e sociedade, com a criação e utilização de indicadores para a melhoria da qualidade dos serviços públicos.

Nesse sentido, o documento estabelece que o governo brasileiro compromete-se a: desenvolver e disponibilizar softwares livres para facilitar tanto a participação do cidadão, quan- 
to a gestão compartilhada das reclamações relativas aos mais diferentes serviços públicos; e elaborar participativamente um normativo para a integração sistêmica das Ouvidorias Públicas Federais.

Assim, conforme prevê Hilgers e Piller (2011), será possível aos cidadãos transmitir sugestões de melhoria e fazer as notificações de reclamações em tempo real. Caracteriza-se aqui um processo de melhoria contínua aberta por meio de colaboração cidadã, o que efetivamente traduz o sistema aberto de inovação pública.

O plano de ação prevê ainda a criação de portal com uma organização de serviços estruturada a partir do ponto de vista do cidadão. Verifica-se, conforme o texto, que o próprio cidadão definirá a estrutura que o sistema apresentará. Também está previsto um estímulo aos cidadãos para participarem do processo de inovação pública.

Especificamente para a área de educação pública o plano de ação reservou uma ação.

Quadro 9

Ação referente aos serviços de educação pública

\begin{tabular}{|c|l|l|}
\hline \multicolumn{1}{|c|}{ Área } & \multicolumn{1}{|c|}{ Ação } & $\begin{array}{c}\text { Classificação no processo } \\
\text { de inovação aberta }\end{array}$ \\
\hline Serviços de Educação & $\begin{array}{l}\text { Painel de Controle do Sistema Integrado de Monitoramento e } \\
\text { Controle (Módulo Público) }\end{array}$ & Transparência/Colaboração \\
\hline
\end{tabular}

Fonte: Elaborado pelos autores (2013).

Vê-se nesse compromisso outra proposta de participação direta dos cidadãos nas políticas públicas. Preocupou-se em definir um compromisso que permita o uso de mecanismos para auxiliar os gestores escolares no monitoramento de ações consideradas estratégicas. Essa ação tem a intenção de permitir a visualização de diversos indicadores dos programas do governo relacionados à educação.

Constata-se que os compromissos firmados no plano de ação brasileiro estão vinculados com a política efetiva de inovação aberta pública. As ações definidas, conforme prevê Hilgers e Piller (2011), estão, em sua maioria, relacionadas ao processo de transparência. Pois, segundo os autores, é com a publicação e disponibilização de todos os processos políticos e administrativos relevantes que o cidadão terá a sensação de possível participação e colaboração futura.

\section{Considerações finais}

A intenção dos autores no desenvolvimento deste estudo foi apresentar uma análise do elemento central de abertura do processo de inovação pública: o Plano de Ação brasileiro apresentado à Open Government Partnership. O documento apresenta propostas de ações que estão relacionadas a transparência fiscal, acesso à informação e, em alguns casos, participação da sociedade. Destaca-se que, neste estudo, não houve intenção de verificar a efetiva execução 
das ações propostas no plano de ação, mas foi focalizada apenas a apresentação dos conceitos teóricos de inovação aberta associados ao documento em questão.

O documento apresenta compromissos que procuram restabelecer um equilíbrio nas novas funções do Estado, que incluem a sociedade na gestão. Muitas das ações estão amparadas nas tecnologias de informação, com vistas a atingir maiores níveis de eficiência e interação com a sociedade. Isso possibilitará uma administração pública preparada para enfrentar os desafios vindouros.

Possibilitar uma gestão pública que leve em conta a participação da cidadania, por meio de mecanismos oriundos da sociedade civil organizada, não significa a exclusão dos poderes constituídos (Tenório e Saraiva, 2006). Ao contrário, essa ação possibilita que a própria dinâmica social acompanhe e sugira ações inovadoras que o Estado não observa com clareza e que a sociedade percebe em função de seus interesses particulares.

Verifica-se, a partir da análise das 32 ações propostas no plano de ação brasileiro, que existe uma preocupação do governo federal com a preparação do corpo estatal (administradores, servidores) para a abertura do processo de inovação. O plano está estruturado de maneira que atende ao proposto por Hilgers e Piller (2011), na medida em que propõe a maioria (31) de suas ações na perspectiva da transparência. Entende-se que o governo federal pretende criar uma estrutura administrativa que permita que os dados relevantes do governo estejam disponíveis aos cidadãos.

Observa-se que algumas ações já permeiam o campo da participação e, segundo o pensamento de Hilgers e Piller (2011), fazem parte de uma segunda etapa do processo de inovação aberta na gestão pública. Essas ações já preveem a participação dos cidadãos nas definições das políticas públicas, ainda que inicialmente estejam relacionadas com o próprio eixo de ação dos dados abertos. Assim, o documento em análise busca enfrentar o desafio de criar no país as condições necessárias para que os cidadãos possam ser inseridos no processo de formulação de políticas inovadoras do governo.

Entretanto, Jacobi e Pinho (2006) alertam que essas experiências que inovam a relação entre Estado e sociedade civil ainda estão longe de representar um paradigma de significativa repercussão no atual quadro brasileiro, principalmente em virtude da falta de vontade política dos governantes e fragilidade do tecido.

Ademais, segundo a OECD (2010), pode existir um grande obstáculo para a efetivação das propostas, que é a possibilidade de uma parcela significativa de cidadãos não estar interessada em participar do processo de inovação aberta pública, ou mesmo considerá-lo como irrelevante ou perda de tempo, isto é, considerá-lo com descrédito. Mas esse motivo não parece razoável para se desistir do desenvolvimento de formas inovadoras de participação pública e de integração.

Como resultado desta reflexão sobre a gestão pública brasileira, pode-se considerar que foi dado um importante passo na direção da inovação aberta: o compromisso brasileiro com a abertura dos processos de inovação a partir da associação do governo brasileiro à OGP, em 2011. O plano de ação brasileiro apresenta uma estrutura e visão geral de como a colaboração e inovação externa poderão oferecer novos caminhos de participação dos cidadãos na admi- 
nistração pública e, ao mesmo tempo, reforça a criação de valor público e pode, futuramente, abrir espaço para propostas inovadoras no processo de tomada de decisão política.

\section{Referências}

ANDRADE, Jackeline A. de. O processo de inovação nas organizações públicas: integrando conceitos às práticas. XXV ENCONTRO ANUAL DA ANPAD, 2001, Campinas.

ANGELIS, Cristiano Trindade. Uma proposta de um modelo de inovação e inteligência governamental. Revista de Administração e Inovação, v. 10, n. 3, p. 297-324, 2013.

ASKOUNIS, Dimitrios et al. Citizens collaboration and co-creation in public service delivery: the COCKPIT Project. International Journal of Electronic Government Research, v. 8, n. 3, p. 33-62, 2012.

BARACCHINI, Sabrina A. A inovação presente na administração pública brasileira. Revista de Administração de Empresas, v. 42, n. 2, p. 104-109, abr./jun. 2002.

BRASIL. Decreto Presidencial não numerado de 15 de setembro de 2011. Diário Oficial da União, 16 set. 2011.

BRASIL. Lei no 12.527 de 18 de novembro de 2011. Diário Oficial da União, 18 nov. 2011. Ed. extra.

CELLARD, André. A análise documental. In: POUPART, Jean et al. A pesquisa qualitativa: enfoques epistemológicos e metodológicos. Petrópolis: Vozes, 2008. p. 295-316.

CHESBROUGH, Henry. W. The era of open innovation. MIT Sloan Management Review, Massachusetts, v. 44, n. 3, p. 34-41, 2003.

CORDEIRO, Antonio et al. Governo eletrônico e redes sociais: informação, participação e interação. R. Eletr. de Com. Inf. Inov. Saúde, v. 6, n. 2, p. 1-8, 2012.

DAMANPOUR, Fariborz; WALKER, Richard M.; AVELLANEDA, Claudia N. Combinative effects of innovation types and organizational performance: A longitudinal study of service organizations. Journal of Management Studies, v. 46, n. 4, p. 650-675, 2009.

DUTTON, William. Networking distributed public expertise: strategies for citizen sourcing advice to government. One of a Series of Occasional Papers in Science and Technology Policy, Science and Technology Policy Institute, Institute for Defense Analyses, Pennsylvania Avenue, Washington DC, 2011.

FARAH, Marta F. S. Inovação e governo local no Brasil contemporâneo. In: JACOBI, Pedro R.; PINHO, José A. G. Inovação no campo da gestão pública local: novos desafios, novos patamares. Rio de Janeiro: FGV Editora, 2006. p. 41-75.

FARAH, Marta F. S. Reforma de políticas sociais no Brasil: experiências recentes. Revista de Administração da USP, v. 33, n. 1, p. 51-59, 1998.

FERRER, Florencia; LIMA, Cristian. Gestão pública eficiente: impactos econômicos de governos inovadores. Rio de Janeiro: Elsevier, 2007. 
FISCHER, Tania. Poder local: um tema em análise. Rev. Adm. Pública, v. 26, n. 4, p. 105-113, 1992. GODOY, Arilda. S. Pesquisa qualitativa: tipos fundamentais. Revista de Administração de Empresas, v. 35, n. 3, p. 20-29, 1995.

HELDER, Raimundo F. Como fazer análise documental. Porto: Universidade de Algarve, 2006.

HILGERS, Dennis et al. Open governance and citizensourcing: applying the idea of open innovation to the public sector. Academy of management annual meeting. Chicago: AOM, 2009. p. 1-30.

HILGERS, Dennis; IHL, C. Citizensourcing: Applying the concept of open innovation to the public sector. International Journal of Public Participation, v. 4, n. 1, p. 67-88, 2010.

HILGERS, Dennis; PILLER F. T. A government 2.0: fostering public sector rethinking by open innovation. Innovation Management, v. 1, n. 2. p. 1-8, 2011.

JACOBI, Pedro R.; PINHO, José Antonio G. Inovação no campo da gestão pública local: novos desafios, novos patamares. Rio de Janeiro: FGV Editora, 2006.

KLERING, Luís R.; ANDRADE, Jackeline A. Inovação na gestão pública: compreensão do conceito a partir da teoria e da prática. In: JACOBI, Pedro R.; PINHO, José A. G. Inovação no campo da gestão pública local: novos desafios, novos patamares. Rio de Janeiro: FGV Editora, 2006. p. 77-97.

MARTINS, Paulo Emílio M.; PIERANTI, Octavio P. Estado e gestão pública: visões do Brasil contemporâneo. Rio de Janeiro: FGV Editora, 2006.

MURRAY, Robin; CAULIER-GRICE, Julie; MULGAN, Geoff. The open book of social innovation. Londres: Nesta, 2010. (Social Innovator Series)

OECD. Building an open and innovative government for better policies and service delivery. Background document for session Expert meeting. Paris: OECD, 2010.

OECD. Citizens as Partners - OECD. Handbook on information, consultation and public participation in policy-making. Paris: OECD, 2001.

OPEN GOVERNMENT PARTNERSHIP. Declaração de governo aberto. set. 2011. Disponível em: <www.opengovpartnership.org/open-government-declaration>. Acesso em: 10 jan. 2013.

OPEN GOVERNMENT PARTNERSHIP. Plano de ação brasileiro. set. 2011. Disponível em: <www. opengovpartnership.org/countries/brazil>. Acesso em: 10 jan. 2013.

PINHO, José Antonio G.; SANTANA, Mercejane W. O que faz o governo municipal no Brasil? Realizações, tendências e perspectiva. In: ENCONTRO DA ANPAD, XXIV, 2000, Florianópolis. Anais... 2000.

POLLIT, Christopher. Managerialism and the public service. Oxford: Blackwell, 1990.

QUEIROZ, Roberta G. M.; CKAGNAZAROFF, Ivan B. Inovação no setor público: uma análise do choque de gestão (2003-2010) sob a ótica dos servidores e dos preceitos teóricos relacionados à inovação no setor público. Rev. Adm. Pública, v. 44, n. 3, p. 679-705, maio/jun. 2010.

RUEDIGER, Marco Aurélio. Perspectivas da governança na era da informação: Estado e sociedade civil. In: MARTINS, Paulo Emílio M.; PIERANTI, Octavio P. (Org.). Estado e gestão pública: visões do Brasil contemporâneo. Rio de Janeiro: FGV Editora, 2006. p. 23-39. 
SÁ-SILVA, Jackson Ronie; ALMEIDA, Cristóvão Domingos de; GUINDANI, Joel Filipe. Pesquisa documental: pistas teóricas e metodológicas. Revista Brasileira de História e Ciências Sociais, São Leopoldo, v. 1, n. 1, p. 1-15, 2009.

SARAIVA, Luiz Alex S.; CAPELÃO, Luiz G. F. A nova administração pública e o foco no cidadão: burocracia $\times$ marketing? Rev. Adm. Pública, Rio de Janeiro, v. 34, n. 2, p. 59-77, mar./abr. 2000.

SAUNDERS, Mark; LEWIS, Philip; THORNILL, Adrian. Research methods for business students. 4. ed. Harlow, England: Pearson Education, 2007.

SILVA, Lidiane. R. C. et al. Pesquisa documental: alternativa investigativa na formação docente. In: CONGRESSO NACIONAL DE EDUCAÇÃO — EDUCERE, IX, ENCONTRO SUL BRASILEIRO DE PSICOPEDAGOGIA, III, 2009, Curitiba.

SPINK, Peter. A inovação na perspectiva dos inovadores. In: JACOBI, Pedro; PINHO, José Antonio G. de (Org.). Inovação no campo da gestão pública local: novos desafios, novos patamares. Rio de Janeiro: FGV, 2006. p. 107-132.

TENÓRIO, Fernando G.; SARAVIA, Enrique J. Escorços sobre gestão pública e gestão social. In: MARTINS, Paulo Emílio M.; PIERANTI, Octavio P. Estado e gestão pública: visões do Brasil contemporâneo. Rio de Janeiro: FGV Editora, 2006. p. 119-159.

TIDD, Joe; BESSANT, John; PAVITT, Keith. Gestão da inovação. 3. ed. Porto Alegre: Bookman, 2008.

TORRES, Lars H. Citizen sourcing in the public interest.Knowledge Management for Development Journal, v. 3, n. 1, p. 134-145, 2007.

TORRES, Marcelo Douglas de F. Estado, democracia e administração pública no Brasil. Rio de Janeiro: FGV, 2004.

VEIGA, Laura da; COSTA, Bruno L. D.; CARNEIRO, Carla B. L. Os desafios da inclusão social: programas de assistência para a infância e juventude vulnerabilizadas na administração municipal de Belo Horizonte. In: JACOBI, Pedro; PINHO, José Antonio G. Inovação no campo da gestão pública local: novos desafios, novos patamares. Rio de Janeiro: FGV Editora, 2006.

VERGARA, Sylvia C. Métodos de pesquisa em administração. São Paulo: Atlas, 2005.

Rony Klay Viana de Freitas é especialista em gestão pública e mestrando em administração pela Universidade Federal de Sergipe (UFS). E-mail: ronyfreitas@gmail.com.

Antonio Luiz Rocha Dacorso é doutor em administração pela Universidade de São Paulo (USP). Professor adjunto do Departamento de Administração e do Mestrado em Administração da Universidade Federal de Sergipe (UFS). E-mail: antoniodacorso@gmail.com. 